\title{
Oxygen toxicity during artificial ventilation
}

\author{
R. A. L . B R E W I S \\ From the Department of Medicine, University of Manchester
}

Repeated pulmonary collapse and changes suggestive of a severe alveolar-capillary diffusion defect were observed over a period of 20 days in a patient who was receiving artificial ventilation $\stackrel{\sim}{\perp}$ because of status epilepticus. Profound cyanosis followed attempts to discontinue assisted ventila- os tion. The Bird Mark 8 respirator employed was found to be delivering approximately $90 \%$ o oxygen on the air-mix setting and pulmonary oxygen toxicity was suspected. Radiological improvement and progressive resolution of the alveolar-capillary block followed gradual reduction $\unlhd$ of the inspired concentration over nine days. The management and prevention of this complication are discussed. The inspired oxygen concentration should be routinely monitored in patients receiving intermittent positive pressure ventilation, and the concentration should not be higher than that required to maintain adequate oxygenation. The Bird Mark 8 respirator has an inherent tendency to develop high oxygen concentrations on the air-mix setting, and the machine should therefore be driven from a compressed air source unless high concentrations of oxygen are essential.

The toxic properties of oxygen have been most widely studied in the context of hyperbaric oxygenation, and the tendency to produce convulsions at partial pressures in excess of 2 atmospheres has been well documented (Bean, 1945, 1965 ; Donald, 1947). Between this pressure and about two-thirds of an atmosphere partial pressure of oxygen, tolerance is limited by the effects upon the lung. Laboratory animals may die with severe pulmonary congestion with intra-alveolar exudation and haemorrhage during exposure after an interval which is variable between species and is dependent upon the partial pressure of oxygen inspired and upon a number of environmental and metabolic factors (Paine, Lynn, and Keys, 1941 ; Bean, 1945, 1965). Information concerning the tolerance by man of sub-convulsive inspired oxygen tensions is scarce. Normal subjects exposed to pure oxygen at atmospheric pressure develop severe substernal distress which usually leads to termination of the exposure after between 48 and 72 hours (Clamann and Becker-Freyseng, 1939 ; Ohlsson, 1947 ; Doležal, 1962 ; Lee, Caldwell, and Schildkraut, 1963). Objectively, a reduction in vital capacity and changes suggestive of impaired alveolarcapillary diffusion have been reported (Comroe, Dripps, Dumke, and Deming, 1945 ; Ernsting, 1961); normality is usually restored within 48 hours of the end of the exposure.

Pulmonary collapse and congestion have come to be recognized as complications of intermittent positive pressure ventilation (I.P.P.V.) and, whilst many factors probably influence their develo ment (Lancet, 1967), attention has been increas ingly directed towards the role of the inspired oxygen concentration. Indirect evidence of tox effects of oxygen has been provided by posf mortem studies (Pratt, 1958 ; Cederberg, Hellste? and Miörner, 1965; Nash, Blennerhassett, and Pontoppidan, 1967). In 75 patients who had received artificial ventilation Nash and his coli leagues demonstrated a clear link between the inspired oxygen concentration and the finding of post-mortem histological changes in the lung resembling those seen in experimental animats dying of oxygen toxicity. Similar changes weige reported in the lungs of a case presented at clinico-pathological conference at the Massach setts General Hospital (Castleman and McNeel, 1967). This patient had multiple injuries and diead with recurrent pulmonary congestion whils st receiving $85 \%$ oxygen by I.P.P.V.

The purpose of the present communication to report the development and subsequent revers of recurrent massive collapse and an appare block in alveolar-capillary diffusion in a patient receiving I.P.P.V. from a respirator which w⿳亠口冋阝 found to be delivering an unexpectedly high cof centration of oxygen.

\section{METHODS}

Until 20 May 1967 (day 20) blood gas analyses were performed on arterialized capillary blood and Pco 
was derived using the Astrup technique. Subsequently all blood gas analyses were performed on arterial blood drawn from an indwelling catheter. Arterial oxygen tension $\left(\mathrm{PaO}_{2}\right)$ was estimated with a Clark platinum electrode and $\mathrm{PCO}_{2}$ with a Severinghaus electrode (both Radiometer, Copenhagen). Gaseous oxygen concentrations were measured with a paramagnetic analyser (Servomex). The ventilator employed was a Bird Mark 8 respirator which was powered by the hospital oxygen system (line pressure 60 p.s.i.). It was used on the 'air-mix' setting throughout and no 'negative phase' was employed.

\section{CASE REPORT}

The patient, a woman aged 33, developed status epilepticus after an adjustment of her anticonvulsant therapy, and this persisted despite recommencement of the drugs and administration of paraldehyde, intravenous diazepam, and two periods of deep chloroform anaesthesia. She was admitted to Manchester Royal Infirmary on 1 May 1967 (day 1) after 48 hours of status epilepticus. The seizures were relieved only temporarily by intravenous diazepam, $10 \mathrm{mg}$. An endotracheal tube was passed after the administration of thiopentone, $0.2 \mathrm{~g}$., and suxamethonium, $50 \mathrm{mg}$. i.v., and I.P.P.V. using a Bird Mark 8 respirator was begun. A minute ventilation of 8.5 litres was maintained with an end-tidal pressure of $14 \mathrm{~cm}$. water.

On the morning of the second day a chest radiograph was seen to be entirely normal (Fig. 1). For 48 hours a constant infusion of thiopentone was maintained at a rate of approximately $60 \mathrm{mg}$./hour. The rate was increased briefly if the fits became more frequent, and suxamethonium was infused as necessary to keep the convulsions to a minimum. Phenobarbitone, sodium phenytoin, and diazepam were given intravenously, and primidone by nasogastric tube.

On the morning of the fourth day it was noted that the minute ventilation was falling and that a higher end-tidal pressure of $24 \mathrm{~cm}$. water was necessary to maintain adequate ventilation. At one point the minute ventilation fell briefly to $31 . / \mathrm{min}$. and the $\mathrm{PCO}_{2}$ rose to $78 \mathrm{~mm}$. $\mathrm{Hg}$, having been between 39 and $42 \mathrm{~mm}$. $\mathrm{Hg}$ ever since the start of I.P.P.V.

A chest radiograph taken on the morning of the fourth day showed complete collapse-consolidation of the left lung and of the right upper lobe (Fig. 2). Later, during day 4 , the pulse rate rose to $140 / \mathrm{min}$. and tracheostomy was performed. Profound cyanosis was noted whilst breathing air for short periods at the time of this procedure. Bronchoscopy revealed no obstruction or excess of secretions. The jugular venous pulse was not elevated and there was no peripheral oedema. Widespread crepitations were audible throughout the chest, and these persisted throughout the ensuing three weeks. On the fifth day ventilation was easier and the $\mathrm{PCO}_{2}$ was $43 \mathrm{~mm}$. The chest radiograph was unchanged apart fram the appearance of a new opacity in the right lower lobe. Brochoscopy was performed again on the evening of the fifth day, but no obstruction was seen. A chest radiograph was taken on the following morning and showed partial re-aeration of the left upper lobe and patchy aeration of the right upper lobe with partial resolution of the opacity in the right lower lobe (Fig. 3). She continued to have frequent convulsions whenever the infusion was interrupted until the seventh day, when she was intermittently conscious between seizures which had become milder.

On the seventh day further improvement in the chest radiographic appearances was noted (Fig. 4), for no apparent reason, but partial collapse of the right upper and part of the left lower lobe persisted. This was more marked the following day, and by the ninth day the right upper lobe was once more collapsed and densely opacified and there was consolidation at the left base (Fig. 5). All areas of opacification had extended by the tenth day, and on the following day numerous fluffy, radially arranged oval shadows. $0.5-1 \mathrm{~cm}$. in diameter, were evident in the relatively well-aerated regions. Ventilation was not difficult at this stage, the patient was fully conscious and appeared well, occasionally triggering the machine and ventilating $10 \mathrm{l} / \mathrm{min}$. with a respiratory rate of $17 / \mathrm{min}$. and an end-inspiratory pressure setting of $20 \mathrm{~cm}$. $\mathrm{H}_{2} \mathrm{O}$.

I.P.P.V. was continued because severe respiratory distress and deep cyanosis accompanied even brief interruptions for toilet to the trachea. Bronchoscopy was repeated on the eleventh day and again no bronchial obstruction was seen. A chest radiograph the following day showed the reappearance of pockets of air in the collapsed right upper lobe with persistence of the generalized mottling (Fig. 6). On the following day the upper lobe was again seen to be collapsed and densely opacified. On the fifteenth day the right upper lobe was found to be almost completely re-expanded, but there was now patchy opacification of the right lower lobe (Fig. 7). Over four days there was progressive opacification of this area (Fig. 8), and three areas of opacity, 3 to $4 \mathrm{~cm}$. in diameter, appeared in the left lung field.

On the fifteenth day the $\mathrm{PaO}_{2}$ was $160 \mathrm{~mm}$. $\mathrm{Hg}$ whilst on the ventilator. Every morning for the following three days she was left off the respirator for between 15 and 40 minutes. During the interruption the arterial $\mathrm{Po}_{2}$ fell to between 40 and $45 \mathrm{~mm}$. $\mathrm{Hg}$ on each occasion. The inspired oxygen concentration during this period is unknown (a B.O.C. humidifier delivering $67 \%$ oxygen at $101 . / \mathrm{min}$. was attached to the tracheostomy tube by a T-tube with a distal limb of $50 \mathrm{ml}$.).

On day 20 the oxygen concentration of mixed expired air collected whilst the patient was on the respirator was found to be between 88 and $91 \%$. The respirator appeared to be functioning normally, and its performance was extensively studied. The patient was changed to another respirator of the same type, and this produced similar expired oxygen concentra- 


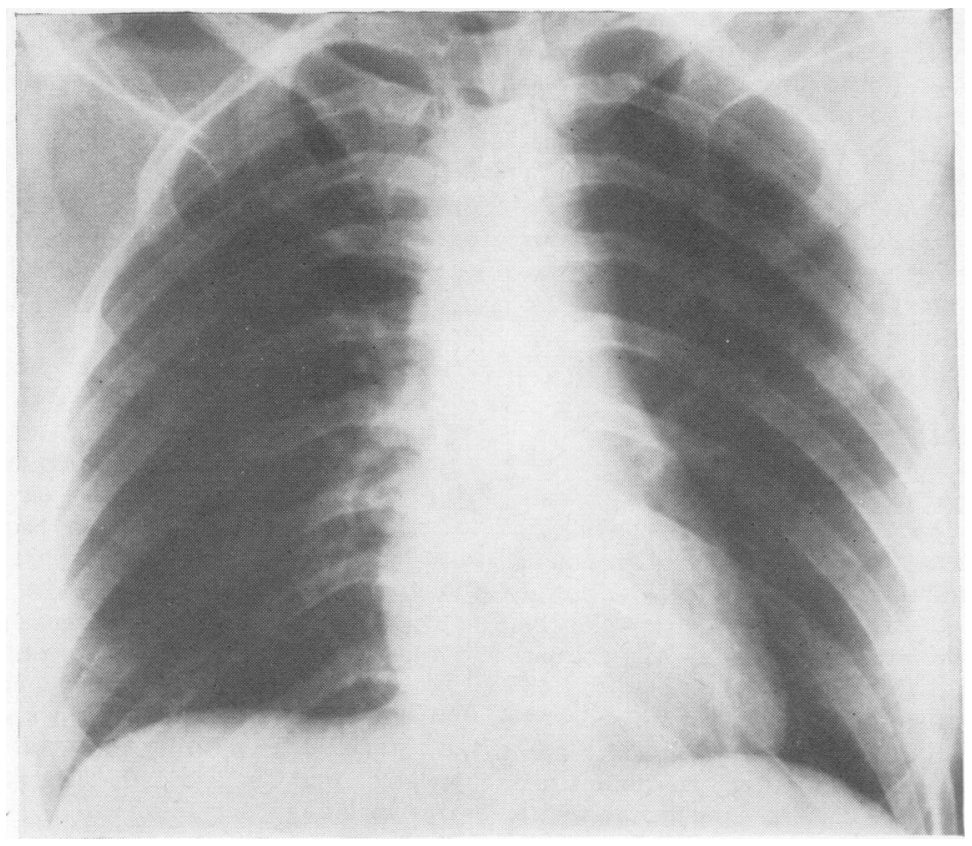

FIG. 1. Radiograph on day 2.

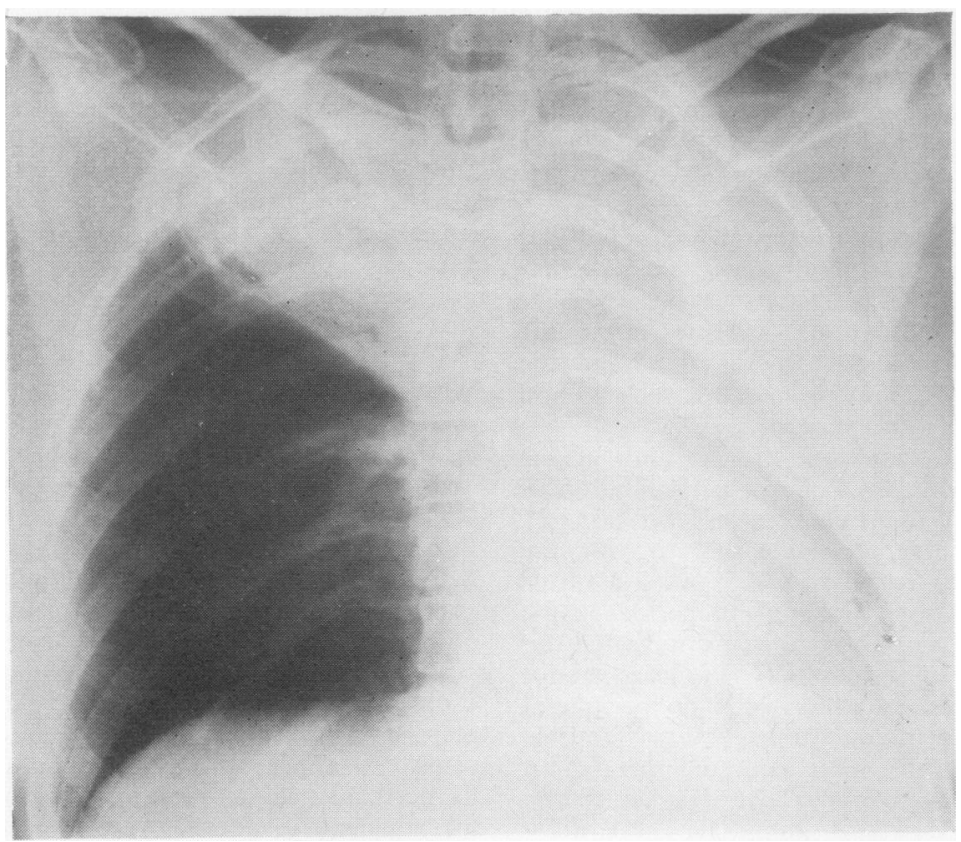

FIG. 2. Radiograph on day 4 . 


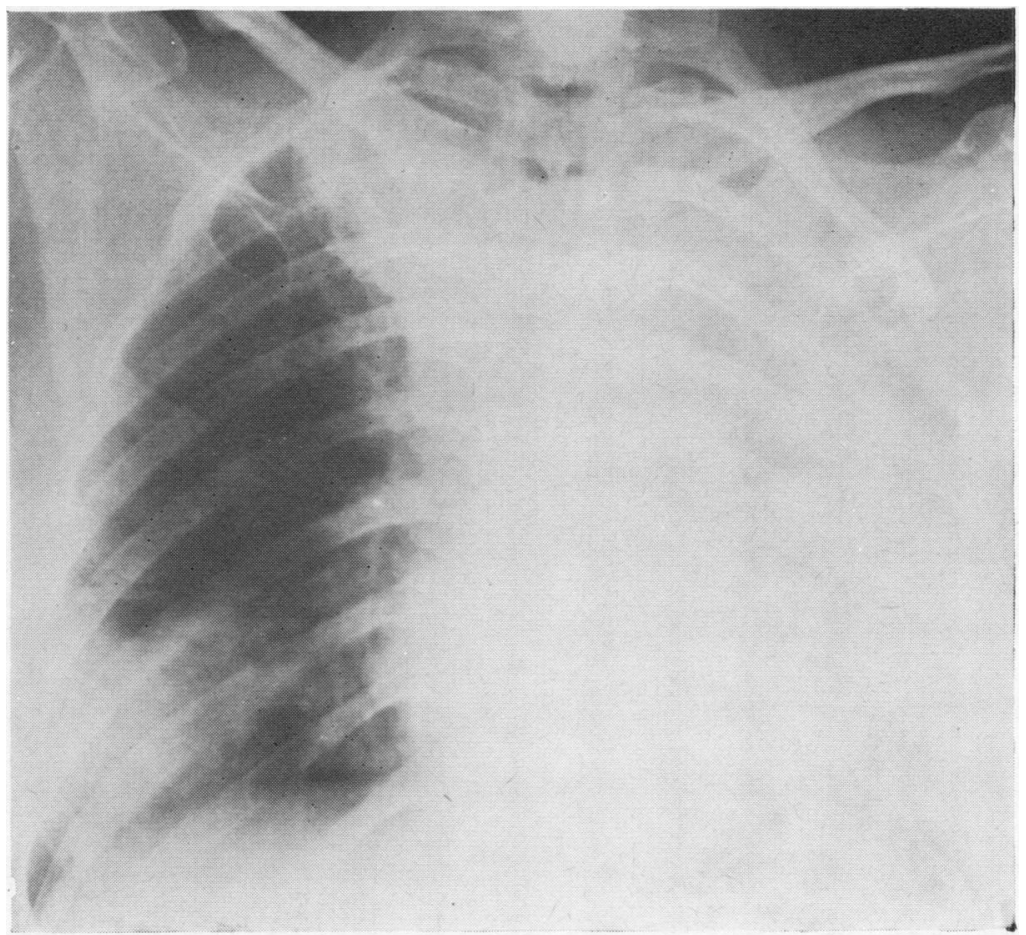

FIG. 3. Radiograph on day 5.

FIG. 4. Radiograph on day 7. 


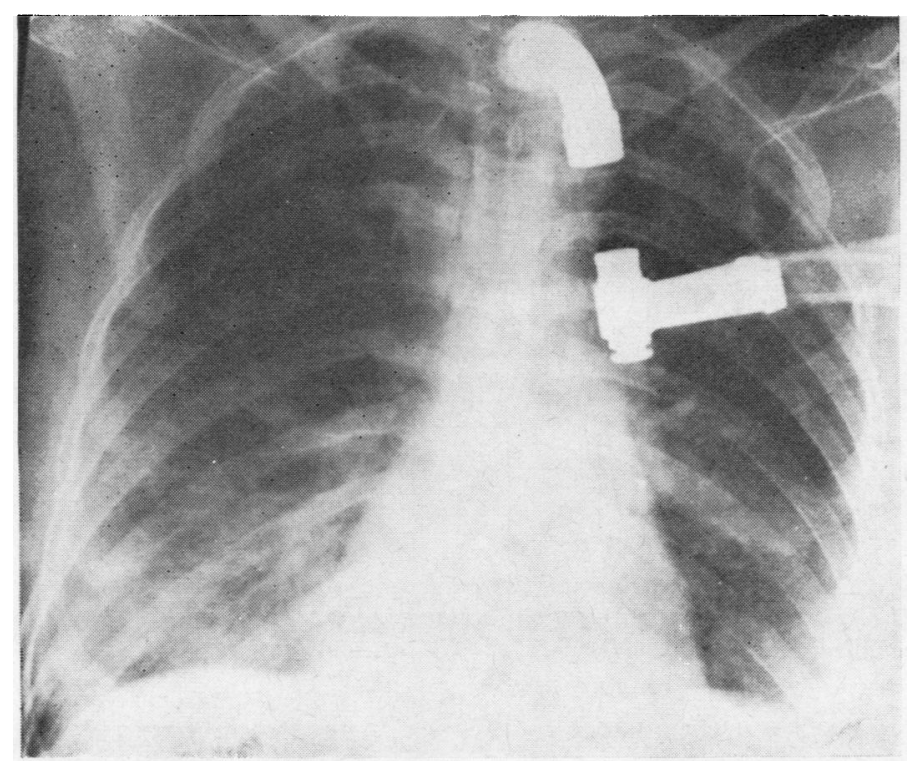

FIG. 7. Radiograph on day 15.

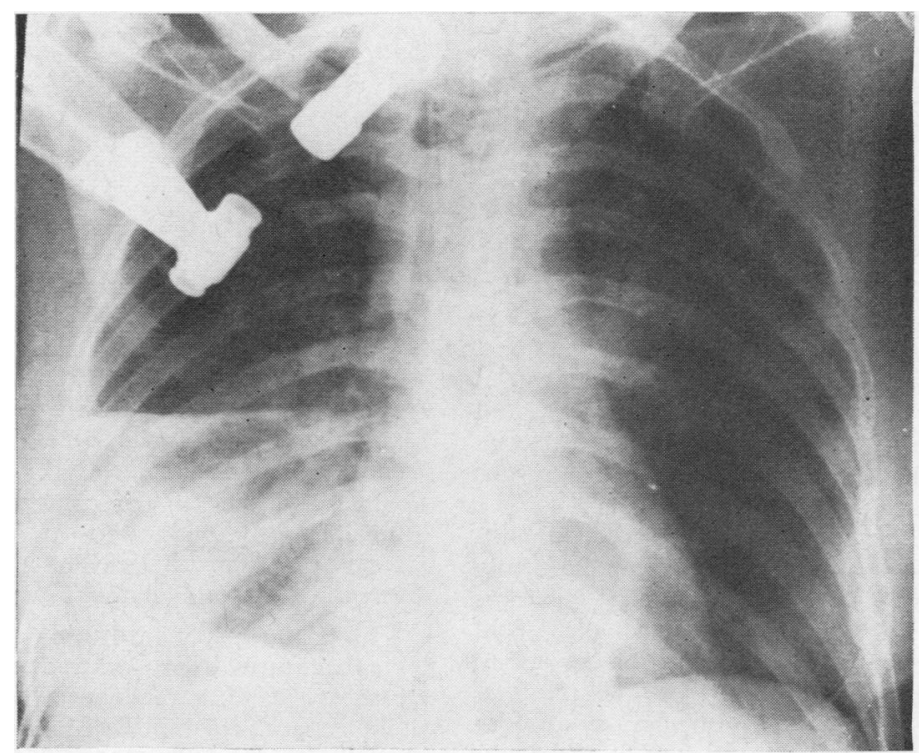

FIG. 8. Radiograph on day 19. 


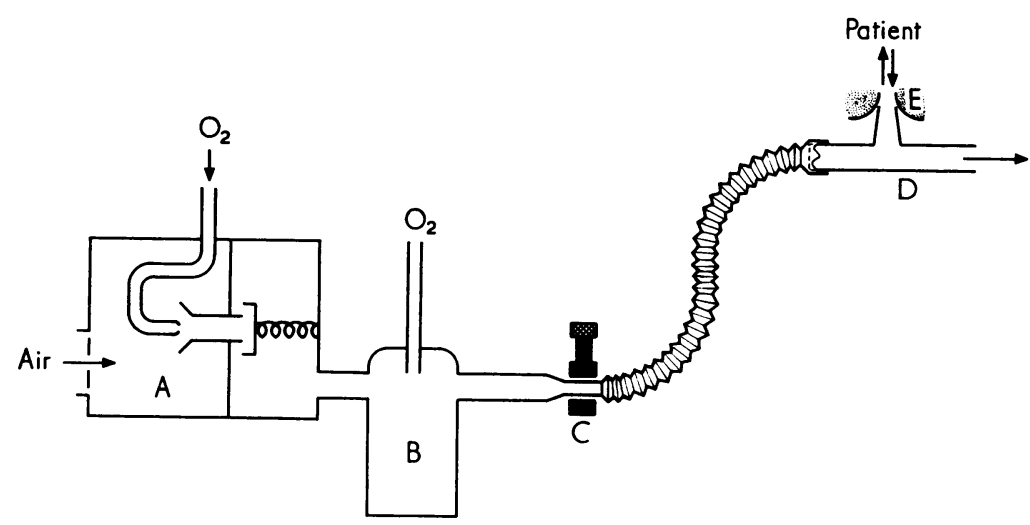

FIG. 9. Diagram to illustrate the use made of the Bird ventilator to provide a controlled inspired oxygen concentration for spontaneous breathing. $(A)$ Bird respirator; (B) nebulizer; (C) clamp; (D) T-tube; (E) tracheostomy tube.

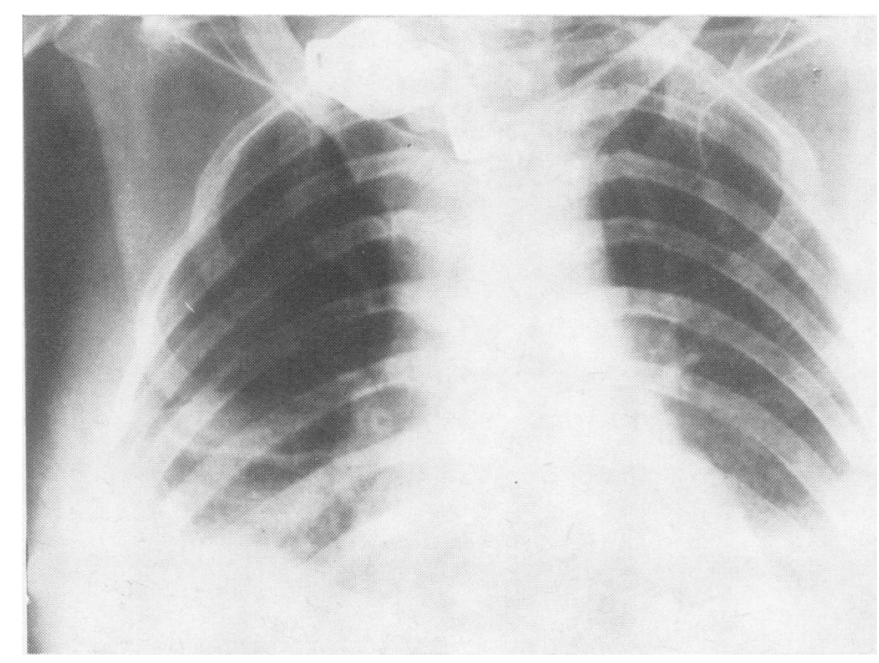

FIG. 10. Radiograph on day 30.

tions over a fairly wide range of settings. The arterial $\mathrm{PO}_{2}$ whilst on the respirator was $160 \mathrm{~mm}$. $\mathrm{Hg}$, and after 5 minutes breathing air fell to $30 \mathrm{~mm}$. Arterial $\mathrm{Po}_{2}$ was estimated at various levels of inspired oxygen concentration (Table).

The patient thereafter breathed spontaneously without assistance and was supplied with oxygen carefully adjusted to maintain $\mathrm{PaO}_{2}$ at $60 \mathrm{~mm}$. $\mathrm{Hg}$. This was conveniently achieved by connecting the Bird respirator with its nebulizer to a T-tube so as to deliver an uninterrupted flow (approx. $70 \mathrm{l} . / \mathrm{min}$.) of $45 \%$ oxygen $^{1}$ (Fig. 9). The concentration of oxygen was then increased as desired by partially restricting

${ }^{1}$ Liquid oxygen supplied to the hospital costs about £2 7 s. per 24 hours at $701 . / \mathrm{min}$ of $45 \%$ the flow by means of a clamp on the tubing whin raised the pressure in the right-hand half of the respirator, thereby reducing the entrainment of air by the Venturi. Repeated arterial $\mathrm{Po}_{2}$ estimations were pepformed and the oxygen concentration was frequennoy adjusted to maintain $\mathrm{PaO}_{2}$ at $60 \mathrm{~mm}$. $\mathrm{Hg}$. Flow was always sufficient to prevent breathing of room $2 \mathrm{ar}$ from the open end of the T-tube.

From the time of instituting this regimen, the radislogical features improved and no new opacities developed. By day 26 the chest radiograph showed only slight generalized mottling and a persistent small aro of collapse at the right base (Fig. 10). Oxygenation became progressively easier and after seven days col centrations lower than $45 \%$ were tolerated. The 


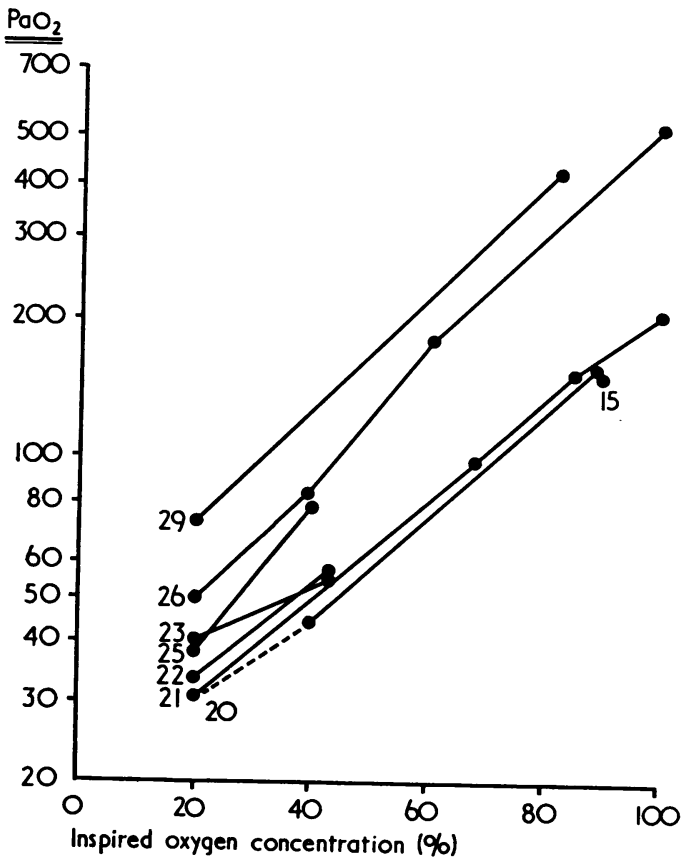

FIG. 11. Inspired oxygen concentration per cent and simultaneous arterial oxygen tension $\left(\mathrm{PaO}_{2}\right) . \mathrm{PaO}_{2}$ is plotted logarithmically. Observations performed on the same day are joined together and the dates are indicated by adjacent numerals. There is progressive improvement in arterial oxygenation after day 20.

T A B L E

INSPIRED OXYGEN CONCENTRATION AND SIMULTANEOUS ARTERIAL GAS TENSIONS

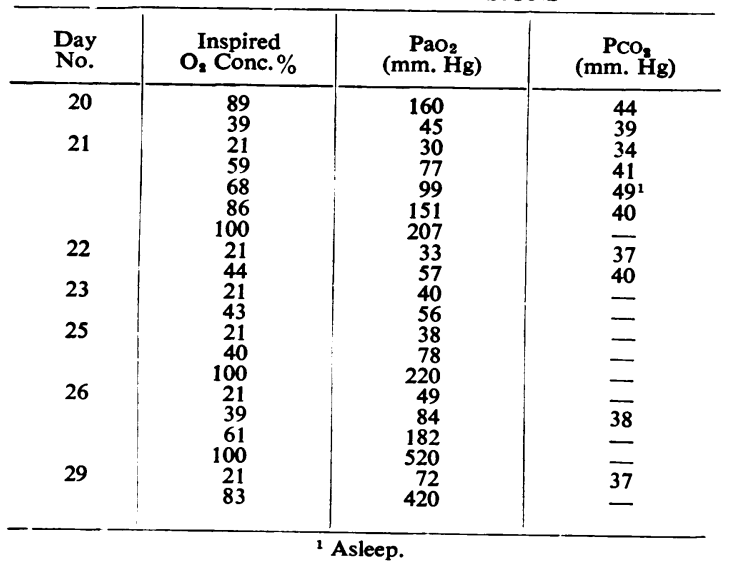

respirator was then replaced by a B.O.C. nebulizer, and the oxygen supply to this was adjusted to maintain the desired $\mathrm{Po}_{2}$. Each day she was allowed to breathe air for a trial period of 5 minutes and the $\mathrm{PaO}_{2}$ at the end of this period rose from an initial level of $30.5 \mathrm{~mm}$. on day 20 to $71.5 \mathrm{~mm}$. on day 29 (Table and Fig. 9). From day 29 she was not cyanosed breathing air, and oxygen was therefore withdrawn. She became cyanosed on even slight exertion at this stage, but there was progressive improvement in her effort tolerance, and she was free from symptoms and had no physical signs at the time of her discharge three weeks later.

\section{DISCUSSION}

In this patient, massive pulmonary collapse developed after only three days of I.P.P.V., during which she was presumably receiving at least $88 \%$ oxygen. Collapse is known to follow shallow controlled respiration if occasional deep inspirations are not taken (Bendixen, Hedley-Whyte, and Laver, 1963), and whilst this may have been a factor in the first few days of assisted ventilation, it does not explain the repeated episodes of collapse later when the patient was conscious and able to take spontaneous deep breaths. Déry, Pelletier, Jacques, Clavet, and Houde (1965) showed that breathing oxygen may lead to a reduction by up to $25 \%$ of the functional residual capacity after only one hour in anaesthetized subjects and that this may be prevented by including nitrogen in the inspired mixture. Lack of nitrogen may have been important in the production of collapse in the present case. It is of interest that there was re-aeration of collapsed areas of lung following both bronchoscopies, even though these comprised merely inspection. It seems possible that some re-nitrogenation took place during lung inflations.

Although shunting of blood through areas of collapse was undoubtedly the main functional abnormality early in the course of the pulmonary complication, later on cyanosis persisted despite considerable radiological clearing. Arterial oxygen tension was measured at various levels of inspired oxygen concentration and it was found that the increase in $\mathrm{PaO}_{2}$ for a given increase in inspired oxygen concentration was greater than would have been expected if the hypoxia had been the result of collapse alone. This suggests that, at this stage, the defect was, in part at least, an alveolarcapillary diffusion block. This diffusion defect is entirely compatible with the histological features attributed to oxygen toxicity reported in the postmortem and animal studies referred to earlier. Prominent among the changes seen here are intra- 
alveolar exudation, sometimes associated with hyaline membrane formation and thickening and later fibrosis of the alveolar walls.

Between day 15 and day 20 the alveolarcapillary block appeared to remain unchanged, i.e., the $\mathrm{PaO}_{2}$ for any given inspired concentration of oxygen was constant. However, after the patient was established on lower levels of inspired oxygen on the 20th day, there was progressive improvement in oxygen transfer, so that for any inspired oxygen concentration there was an increase in $\mathrm{PaO}_{2}$ day by day (Fig. 11). This suggests a cause and effect relationship between the high inspired oxygen concentrations and the diffusion defect.

Considering the widespread use of I.P.P.V., it is perhaps surprising that pulmonary changes such as those described here have not been more widely reported. There seem to be several possible explanations for this. In animals it has been shown that diffuse pulmonary disease (Ohlsson, 1947) and the presence of a right-to-left shunt (Winter, Gupte, Michalski, and Lamphier, 1966) both exert strong protective effects against the development of the pulmonary complications of hyperoxia. Cyanosed patients with these disorders are the most likely to be given high oxygen concentrations and it seems that, paradoxically, they may also be the patients least likely to develop pulmonary reactions.

In patients with essentially normal lungs who require assisted ventilation (for coma, paralysis, etc.), high concentrations of oxygen are unlikely to be prescribed. The present case, however, highlights the fact that, with at least one widely used respirator, high oxygen concentrations may be achieved at settings the manufacturer claims should produce lower concentrations. When pulmonary complications occur in these circumstances, hyperoxia will not be suspected as a cause.

Several authors have described a pulmonary disorder, usually occurring during the resuscitation of gravely ill patients, which comprises radiological signs of congestion and collapse, a reduction in lung compliance, and a progressive alveolar-capillary block which may lead to death due to anoxia. With the exception of the postmortem studies referred to earlier, high inspired oxygen tensions have not been incriminated as the cause of the disorder. Linton, Walker, and Spoerel (1965), using Bird respirators, described six patients with a potentially favourable prognosis in whom progressive and ultimately fatal pulmonary congestion developed. They termed the condition 'respirator lung' and interpreted the radiological changes as 'extensive bronchopne monia', believing that bacterial infection was responsible. Berry and Sanislow (1963) used the term 'congestive atelectasis' for an esentially iders tical syndrome and associated it with inappr\% priate intravenous therapy and reduced alveolar surfactant. More recently, Ashbaugh, Bigelow. Petty, and Levine (1967) have described 'acute respiratory distress in adults' having the same clinical and histological features already describe All except two of their 12 cases were receivinis oxygen; five were receiving concentrations greates than $70 \%$, and a further two were receiving $40 \%$ with a Bennett P.R.I. respirator, which has alread $\$$ been shown to be capable of producing over $70 \%$ oxygen under working conditions (Fairley and Britt, 1964). Oxygen toxicity was discounted as cause of the relatively early appearance of the pulmonary changes. The duration of the oxyge pressure is not stated, but the mean interva between the onset of the illness and respiratory distress of 47 hours and the high concentrations employed suggest that oxygen toxicity may possibly have been discounted on slender ground In our patient gross changes were present afte only 60 hours of I.P.P.V.

TREATMENT Reduction of the inspired oxyge concentration is clearly the most urgent considera $\overrightarrow{\vec{B}}$ tion. The level to which this may be lowered ma be limited, as in the present case, by the resultan fall in arterial oxygen tension. The meagre eve dence available suggests that concentrations excess of $60 \%$ are capable of producing pu monary changes (Comroe et al., 1945), but there is no information concerning the level to which must be lowered to allow reversal of the process. Lowering the oxygen concentration to a level jus sufficient to maintain an arterial $\mathrm{Po}_{2}$ of between 50 and $60 \mathrm{~mm}$. $\mathrm{Hg}$ allows some margin of safety but it might be necessary, in severe cases, if the concentration is still high at this $\mathrm{PaO}_{2}$, to accep the risk of anoxia at lower levels. The position may be said to be irreversible when anoxia prevents lowering of the inspired oxygen tension to level which permits recovery of the pulmonary process. Such a situation is recognized to occur in animals (Paine et al., 1941 ; Bean, 1945), but is remains uncertain whether the process is eve irreversible in man; extracorporeal artificial oxy? genation might be contemplated if it did arise.

If shallow respiration has been a feature, perieํำ odic hyperinflation or the addition of a positive्ष and expiratory pressure may help in re-expanding collapsed areas. Small elevations in alveolar CO 
concentration which would normally be harmless have been shown greatly to aggravate the pulmonary effects of oxygen (Paine et al., 1941; Ohlsson, 1947), and for this reason great care should be taken to ensure that even mild hypoventilation does not occur. Corticosteroids and adrenaline have been shown by Bean and Smith (1953) to enhance the pulmonary effects of oxygen and, pending further studies, they should probably be withheld. Sympathetic blocking agents, Trisbuffer, and chlorpromazine have all been shown to exert a protective effect against pulmonary oxygen toxicity in experimental animals (Johnson and Bean, 1954 ; Bean, 1956, 1961), but it is not known whether they influence the established condition.

PREVENTION Present evidence suggests that if pulmonary oxygen toxicity is to be avoided, no patient should receive more than $60 \%$ oxygen unless this level is insufficient to maintain an arterial $\mathrm{Po}_{2}$ of $60 \mathrm{~mm} . \mathrm{Hg}$.

Green (1967) has shown that the Polymask (British Oxygen Co.) and the Pneumask (Oxygenaire), among the most efficient oxygen masks in general use, may produce in experimental circumstances levels significantly in excess of $60 \%$, but it is probable that sustained high levels are less likely in practice, particularly if high rates of flow are not used. The patients most at risk are those receiving I.P.P.V. When $100 \%$ oxygen is employed the risk is obvious, but the present case highlights the tendency of one widely used respirator to develop high concentrations on the air-oxygen mixture setting.

The Bird Mark 8 respirator (the Mark 7 is essentially similar) is a pressure-limited ventilator designed to run from a source of compressed oxygen. On the air-mix setting air is added to the inspired mixture by a Venturi driven by a fine jet of oxygen. As the pressure within the respirator rises, the Venturi becomes less efficient and ultimately flow ceases. The remainder of inspiration is effected by pure oxygen supplied to the nebulizer. The concentration of oxygen developed is dependent upon the effective compliance of the subject ventilated and upon the flow and pressure settings of the ventilator (Stoddart, 1966). At low flow settings the Venturi jet is weak and less air is entrained; at high pressure settings and when the compliance is reduced the Venturi ceases to work relatively earlier in inspiration, and under all these conditions the concentration of oxygen delivered is higher. There is clearly a need for a variable high-pressure mixing valve, which would enable the ventilator to be driven by any preselected oxygen-air mixture. A limited degree of control is afforded by a recently developed valve (Bird parallel inspiratory flow-mixing cartridge 1289), which enables a variable oxygen-air mixture to be supplied to the nebulizer of an air-driven ventilator. The actual mixture delivered cannot, however, be determined from the settings.

Implicit in the discussion of the prevention of oxygen toxicity is the clear necessity for routine monitoring of the inspired oxygen concentration.

I am grateful to Dr. L. A. Liversedge for permission to publish details of the case.

\section{REFERENCES}

Ashbaugh, D. G., Bigelow, D. B., Petty, T. L., and Levine, B. E. (1967). Acute respiratory distress in adults. Lancet, 2, 319.

Bean, J. W. (1945). Effects of oxygen at increased pressure. Physiol. Rev., 25, 1.

(1956). Reserpine, chlorpromazine and the hypothalamus in reactions to oxygen at high pressure. Amer. J. Physiol., 187, 389. (1961). Tris buffer, $\mathrm{CO}$, and sympatho-adrenal system in reactions to $\mathrm{O}_{2}$ at high pressure. Amer. J. Physiol., 201, 737.

(1965). Factors influencing clinical oxygen toxicity. Ann. N.Y. Acad. Sci., 117, Art 2, p. 745.

- and Smith, C. W. (1953). Hypophyseal and adrenocortical factors in pulmonary damage induced by oxygen at atmospheric pressure. Amer. J. Physiol., $172,169$.

Bendixen, H. H., Hedley-Whyte, J., and Laver, M. B. (1963). Impaired oxygenation in surgical patients during general anesthesia with controlled ventilation. New Engl. J. Med., 269, 991.

Berry, R. E. L., and Sanislow, C. A. (1963). Clinical manifestations and treatment of congestive atelectasis. Arch. Surg., 87, 153.

Castleman, B., and McNeely, B. U. (Editors) (1967). Case records of the Massachusetts General Hospital; Case 7-1967. New Engl. J. Med., 276, 401.

Cederberg, A., Hellsten, S., and Miörner, C. (1965). Oxygen treatment and hyaline pulmonary membranes in adults. Acta path. microbiol. scand., 64, 450 .

Clamann, H. G., and Becker-Freyseng, H. (1939). Einwirkung des Sauerstoffs auf den Organismus bei höherem als normalem Partialdruck unter besonderer Berücksichtigung des Menschen. Luftfahrtmedizin, 4, 1.

Comroe, J. H., Jr., Dripps, R. D., Dumke, P. R., and Deming, M. (1945). Oxygen toxicity. The effect of inhalation of high concentrations of oxygen for twenty-four hours on normal men at sea level and at a simulated altitude of 18,000 feet.J. Amer. med. Ass. $128,710$.

Déry, R., Pelletier, J., Jacques, A., Clavet, M., and Houde, J. (1965), Alveolar collapse induced by denitrogenation. Can. Anaesth. Soc. J., 12, 531 .

Doležal, V. (1962). Some humoral changes in man produced by continuous oxygen inhalation at normal barometric pressure. Riv. Med. aeronaut., 25, 219.

Donald, K. W. (1947). Oxygen poisoning in man. Brit. med. J., 1, 667.

Ernsting, J. (1961). The effect of breathing high concentrations of oxygen upon the diffusing capacity of the lung in man. J. Physiol. (Lond.), 155, $51 P$.

Fairley, H. B., and Britt, B. A. (1964). The adequacy of the air-mix control in ventilators operated from an oxygen source. Canad. med. Ass. J., 90, 1394.

Green, I. D. (1967). Choice of method for administration of oxygen. Brit. med. J., 3, 593.

Johnson, P. C., and Bean, J. W. (1954). Sympathetic nervous activation as a contributor to the adverse effects, particularly pulmonary damage and edema, induced by $\mathrm{O}_{2}$ at high pressure. Amer. I Physiol., 179, 648.

Lancet (1967), Annotation: Pulmonary respirator syndrome. Lancet, 1, 992. 
Lee, W. L., Caldwell, P. B., and Schildkraut, H. S. (1963). Changes of lung volume, diffusion capacity and blood gases in oxygen toxicity in humans. Fed. Proc., 22, 395.

Linton, R. C., Walker, F. W., and Spoerel, W. C. (1965). Respirator care in a general hospital: a five-year survey. Canad. Anaesth. Soc. J., 12,450 .

Nash, G., Blennerhassett, J. B., and Pontoppidan, H. (1967). Pulmonary lesions associated with oxygen therapy and artificial ventilation. New Engl. J. Med., 276, 368.

Ohlsson, W. T. L. (1947). A study on oxygen toxicity at atmospheric pressure. Acta med. scand., Suppl. 190.
Paine, J. R., Lynn, D., and Keys, A. (1941). Observations on thס effects of the prolonged administration of high oxygen concen tration to dogs. J. thorac. Surg., 11, 151.

Pratt, P. C. (1958). Pulmonary capillary proliferation induced b oxygen inhalation. Amer. J. Path., 34, 1033. Stoddart, J. C. (1966). Some observations on the function of the
Bird Mark 8 ventilator. Brit. J. Anaesth., 38, 977 .

Winter, P. M., Gupte, R. K., Michalski, A., and Lanphier, E. $H \vec{\nabla}$ (1966). Modifications of hyperbaric oxygen toxicity by experimental venous admixture. Physiologist, 9, 321. 